toxicity and showed a complete response [Figure 3]. Patient is on regular follow-up and disease free at two and a half year follow-up.

A Kangri is an indigenous portable warming device in

\section{Recurrent Kangri cancer treated with external beam radiotherapy on a cobalt unit}

Sir,

The presentation and spectrum of skin cancer in $K$ ashmir valley of Indian subcontinent is drastically different from rest of the country. Maxwell, in 1819 first reported skin cancer of the lower extremities in Kashmiri population attributing it to the use of $\mathrm{K}$ angri. ${ }^{[1]} \mathrm{U}$ nlike skin cancers in general the biological behavior of these cancers is very aggressive with a substantial risk of loco-regional metastasis in 20$50 \%$ cases. $^{[2,3]}$ Surgery is the frequent modality of treatment used in the management of these tumors. We want to share our experience with use of external beam radiotherapy alone in a case of recurrent $\mathrm{K}$ angri cancer in the following index case. RT 377/06, a 46-year-old rural female developed itching followed by appearance of nodular swellings on the medial aspect of her right thigh over her previous operated scar (operated eight months earlier for her Kangri cancer). She was a chronic user of $K$ angri since her childhood. H er systemic examination was normal. Local examination revealed 3-4 nodular swellings with irregular margins, crusted surface and an indurated base over the previous operated site and in the background of reticular thermal keratotic lesions (erythema abignae) [Figure 1]. She refused re-do surgery or treatment with electrons however, agreed for an edge biopsy of the lesion which confirmed the diagnosis of squamous cell carcinoma with features of karatoses. Patient was treated on a telecobalt unit and received external beam radiotherapy of $55 \mathrm{~Gy} / 5$ weeks by a direct portal with wax bolus [Figure 2]. She was also given prophylactic radiotherapy of $45 \mathrm{~Gy} / 4$ weeks to her inguino-femoral region. Patient completed the treatment protocol to both the sites without any

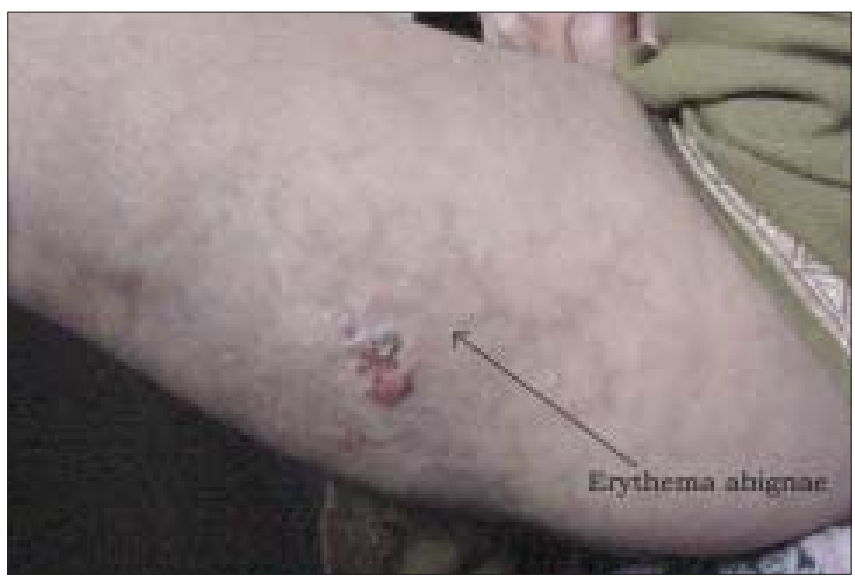

Figure 1: Recurrent Kangri cancer on medial aspect of right thigh (Pre-treatment). Note underlying erythema abignae

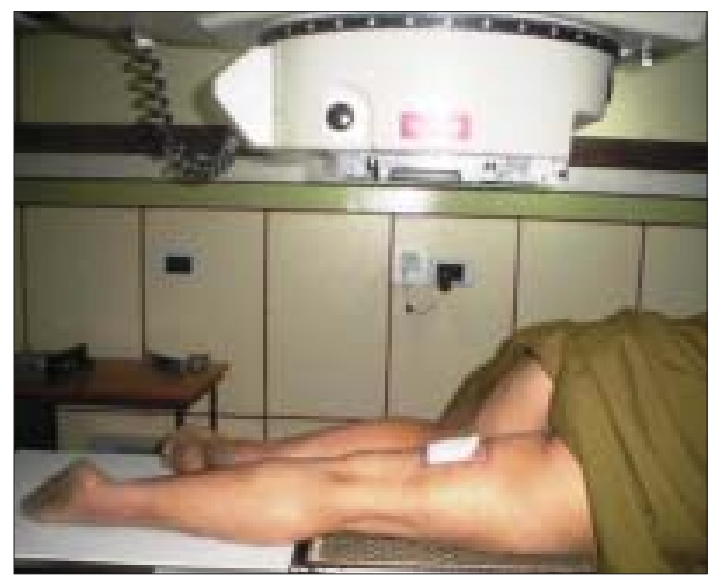

Figure 2: Patient receiving external beam radiotherapy on telecobalt equipment. Note the set-up and wax bolus

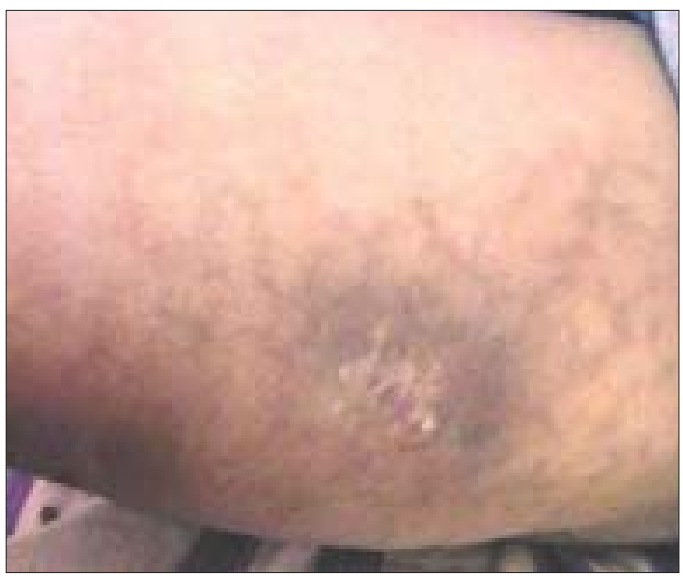

Figure 3: Post- treatment follow-up (at 6 months) showing complete resolution of tumor

Indian Journal of Cancer | July-September 2008 | Volume 45 | Issue 3 
which burning charcoal is carried. The device is usually tucked in-between the thighs/legs or kept in contact with the abdominal wall by Kashmiri population to generate warmth during the winter months. Prolonged use of Kangri induces thermal keratotic changes which take the shape of superficial, serpegenous, reticular blackish brown colored lesions called erythema abignae [Figure 1]. The Kangri cancer starts as a nodule which is often associated with itching, occasional bleeding and ulceration. Because of local nature of this disease entity, there is dearth of literature regarding the treatment policy to be employed in these patients with clinically negative regional nodes and as; the ability to identify subclinical nodal disease prior to its manifestation is limited. ${ }^{[3,4]}$ prophylactic treatment of the regional nodes seems justified on the lines of many head \& neck tumors. Presently, we, at our regional cancer centre are, routinely using prophylactic regional nodal radiotherapy in recurrent and lesions beyond T-2 stage with encouraging results. ${ }^{[5]}$ In this context, use of radiotherapy to primary site whenever indicated with prophylactic regional nodal irradiation has proved its efficacy in reducing the loco-regional relapse and ensured a high cure rate in this peculiar malignancy as exemplified by successful treatment in this index case.

\section{Acknowledgment}

Patient consenting for treatment.

Teli MA, Darzi MA', Gupta M, Katoch SS

Departments of Radiotherapy and 'Plastic and Reconstructive Surgery, SKIMS, Soura, Srinagar-Kashmir, India.

Correspondence to: Dr. Mohmad Ashraf Teli, E-mail: ashrafteli2004@rediffmail.com

\section{References}

1. Maxwell T. Epithelioma in Kashmir. Lancet 1819:152-4.

2. Sanyal B, Shastri SR, Hakim A. A clinical profile of skin cancer from Kashmir Valley with special reference to Kangri cancer. J Clin Radiother Oncol 1989;4:31-6.

3. Khan NA, Shameem A, Kharadi MY. Role of elective irradiation to drainage sites in squamous cell carcinoma of Skin of trunk and extremities. JK Practioner 1999;6:35-8.

4. Koul HK, Goyal RK. A study of Kangri cancer. J Indian Med Practitioners 1968;66:43-6.

5. Ashraf M, Nazir A, Shameem A, Darzi MA. Kangri cancer-Natural history and role of prophylactic nodal irradiation. J Med Physics 2007;32:s 19-20. 